\title{
An evaluation of health warnings in cigarette advertisements using standard market research methods: what does it mean to warn?
}

\author{
Paul M Fischer, Dean M Krugman, James E Fletcher, Richard J Fox, Tina H Rojas
}

\begin{abstract}
Objective - To evaluate the effectiveness of the mandated Surgeon General's warning on cigarette advertisements in comparison to new warnings developed using standard advertising techniques.

Design-Adolescent subjects were exposed in a controlled setting to slide images of advertisements including a Marlboro cigarette advertisement containing either mandated or newly developed warnings.

Setting - Subjects were recruited from, and testing was completed in, high schools from the area of Augusta, Georgia (USA).

Participants - A convenience sample of 220 subjects ranging in age from 13 to 19 years.
\end{abstract}

Intervention-Controlled exposure to either a currently mandated warning or one of three newly developed warnings placed within a cigarette advertisement. Main outcome measures - Post-exposure recall, masked recall, and aided recognition tests were used to evaluate the effectiveness of the warnings' communication. These are standard market research methods that are frequently employed to evaluate print advertisements. Results-The mandated warning performed poorly as a communication device. It was identified as a health advisory, but failed to communicate more specific risk information. Only $15 \%$ of subjects recalled the warning's health concept in the masked recall test. In contrast, newly developed warnings were more effective in communicating specific health information: $66 \%$ recalled the health message. The major elements of the cigarette advertisement were quickly noted and frequently recalled. The median cumulative exposure time required to identify the advertisement as a Marlboro cigarette advertisement was only 0.03 seconds.

Conclusions-The currently mandated warnings on cigarette advertisements fail to communicate specific health risk information effectively. Warnings which are novel, targeted, and developed through a creative process function more effectively as communicating devices.

(Tobacco Control 1993; 2: 279-85)
Introduction

The Federal Cigarette Labeling and Advertising Act of 1965 established the first cigarette warning label in the US. This act required that all cigarette packages be labeled with the warning "Caution: cigarette smoking may be hazardous to your health." In 1969, the Public Health Cigarette Smoking Act attempted to strengthen the warning by changing its wording to read "Warning: the Surgeon General has determined that cigarette smoking is dangerous to your health." In 1972, the Federal Trade Commission (FTC), which is responsible for regulating cigarette advertising, extended this to include warning labels on all cigarette advertisements.

Ongoing concerns regarding the effectiveness of the warning resulted in a 1981 FTC investigation which concluded that the original warning was probably ineffective because it was: (1) overexposed and worn out; (2) no longer novel; (3) abstract and therefore difficult to remember; and (4) not likely to be perceived as personally relevant. ${ }^{1}$ In response to these findings, Congress passed the Comprehensive Smoking Education Act in 1984, which mandated a system of four rotating warnings for cigarette packages and advertisements. In addition, in 1986 Congress passed the Comprehensive Smokeless Tobacco Education Act, which mandated that smokeless tobacco packages and advertisements include one of three warnings printed in a "circle-andarrow" design. This design had been identified by the FTC as one that might draw more attention to the warning. ${ }^{1}$

The product liability implication of tobacco warnings has recently been clarified by the Supreme Court's ruling in the case of Thomas Cipollone v Liggett Group, Inc. ${ }^{2}$ This ruling established that the presence of the warning does not preempt all tort claims against cigarette manufacturers, but does preempt claims based on failure to include more effective warnings after 1969. Successful claims may still be brought if they are based on misrepresentations, fraud, or conspiracy; on failure-to-warn through channels other than labels and advertising; on failure-to-warn in advertising prior to 1969 ; or on strict liability theories. State and local regulatory authorities are subject to these same limitations. By this decision, the Supreme Court eliminated the ability of courts and regulatory agencies to modify the currently mandated warnings.

\author{
University Hospita

$$
\begin{aligned}
& \text { and Mass } \\
& \text { Communication, } \\
& \text { University of Georgia, } \\
& \text { Athens, Georgia, USA } \\
& \text { D M Krugman } \\
& \text { J E Fletcher } \\
& \text { R J Fox } \\
& \text { Medical College of } \\
& \text { Georgia, Augusta, } \\
& \text { Georgia, USA } \\
& \text { T H Rojas } \\
& \text { Correspondence to: } \\
& \text { Paul M Fischer, Section of } \\
& \text { Family Medicine, } \\
& \text { University Hospital, } \\
& \text { Augusta, Georgia } 30912 \text {, } \\
& \text { USA }
\end{aligned}
$$


Therefore, action by Congress will be required to change them.

The accumulated evidence suggests that current tobacco warnings are at best limited in communicating the hazards of smoking. This finding is supported by both surveys and experimental research. In addition to the 1981 FTC report, an eye-tracking study of adolescent subjects viewing cigarette advertisements has shown that only $37 \%$ of subjects look at the warning long enough to read any of its words. ${ }^{3}$ Other research has shown that cigarette warnings are too small to be read on billboard ads and taxicab ads, ${ }^{4,5}$ that they fail to communicate "risk", 6 that they are not believable, ${ }^{7}$ and that they require college-level reading comprehension. ${ }^{8}$ In a study of US cigarette package warnings, the majority of smokers were unfamiliar with even the general themes of the health messages. ${ }^{9}$

An important question is, "What level of communication is necessary, or acceptable, in terms of warning consumers?" After all, communication is not all or nothing, but rather, occurs in steps and exists at various levels of persuasiveness. A great deal of communication research has focused on how information is processed. One of the most notable models divides communication into distinct stages - exposure, attention, comprehension, acceptance, and retention. ${ }^{10}$ Information passes through these stages prior to having an impact on either attitudes or behaviour.

The objectives of the present study were to investigate, in a more comprehensive manner than previous studies, what current warnings actually communicate regarding the hazards of smoking, and to examine whether or not new warnings could provide more meaningful communication. In so doing, the research raises the policy question: "What does it mean to warn?"

\section{Methods}

WARNING DEVELOPMENT

A common strategy for developing advertising copy is to: (1) identify the target audience; (2) establish communication goals; (3) employ a creative team, including graphic artists and communication experts, to develop test copy; (4) evaluate the advertising copy in focus groups made up of individuals in the target audience; and finally (5) use the focus group data to refine the advertising message.

We used this approach to develop new health warnings, targeted to adolescents, which could be integrated into cigarette advertisements. Adolescents were chosen as study subjects because they are at the age when most cigarette experimentation occurs, and therefore when health warnings have the greatest potential to prevent smoking.

The communication goal chosen by the research team was to provide specific and relevant health risk information regarding cigarette use and to present it in a format conducive to the comprehension of risk by adolescents. We wanted to move beyond mere warning notification to understanding and comprehension.

In keeping with what is likely to be acceptable from a policy perspective, the newly developed warnings were identical in size and position to current warnings in advertisements. It should be obvious that huge warnings that dominate an advertisement would be noted by subjects. While large, highly visible health warnings on cigarette packages have been proposed in Australia ${ }^{11}$ and are being implemented in Canada, we considered the likelihood for approval of similar warnings on cigarette advertisements in the US to be low.

A creative team made up of three individuals with extensive commercial design experience was used to develop the new warnings. Other than the communication goals and limitations identified above, the design group was given freedom to use any text, graphics, print type, or colours in developing the test warnings.

Focus groups were used to assess the communication value of the current warnings and to evaluate and refine the new warning concepts. Focus groups are a form of qualitative research that is widely used to explore consumer practices and perceptions. ${ }^{12}$ They involve structured discussion with a small group of subjects, and often employ stimulus materials (ie, test advertisements). All groups were led by experienced moderators.

Two initial focus groups were conducted in the Atlanta metropolitan area with high school students between 14 and 17 years of age. All group participants had used cigarettes (at least one cigarette in the past 30 days). One group had six males and four females. The other had four males and six females. These groups were designed to gain a greater understanding of adolescents' decisions regarding cigarette use, their reactions to tobacco advertising, their beliefs regarding health risks, and their reactions to the four currently mandated warnings.

In general, the focus group participants were aware that cigarette advertisements contained a warning, but they displayed limited knowledge of the specific health messages. A typical comment by a teenager was, "It's something about health."

Several conclusions were drawn from testing the preliminary ideas developed by the creative team. First, the warning's message had to have an immediate consequence. Distant health outcomes were not personalised. Second, the use of colloquial language could backfire. Terms such as "dude" seemed incongruent with a warning. For a warning to be credible, it should be serious and authoritative. Finally, simplicity was important. Short phrases or graphic techniques could best communicate risk.

Based on insight from these focus groups, the creative team developed a series of five refined warnings and incorporated them into several current cigarette advertisements. These advertisements were selected from the magazines read by subjects in the target group.

A second set of two focus groups, each with 10 high school students (ages 14-17 years) was held in Augusta, Georgia, USA. Each group 
was made up of five males and five females. The purpose of these groups was to examine both the creative concepts and graphic presentations of the new warnings and to compare them with the mandated warnings. The two groups were again recruited based on their experience with cigarettes (at least one cigarette in the past 30 days). Video tape recordings and transcripts of those focus groups were reviewed by members of the creative team and the research team. Conclusions drawn from these focus groups included:

- Humour is ineffective. Teenagers stated that smoking is a serious issue and should be treated accordingly.

- The use of popular figures is problematic. A test warning, "Bo says, don't do it" was not believable. As one subject stated, "Bo may be able to sell sneakers, but what does he know about smoking?"

- Fewer words, larger type, contrasting colours, and graphic devices all increased attention to the warning.

- Simple, straightforward messages were more effective than the existing warnings in communicating health risk.

Based on the results on the focus groups, the creative team developed three new warning formats to compare to a currently mandated warning in the experimental phase of the research (see figure 1). "Smokers inhale carbon monoxide" gained attention. "Carbon monoxide" was understood to be a poisonous gas and because of its association with teen suicide, it was more personalised as a health risk by subjects than "emphysema" or "heart disease." This warning was tested with both white and bright yellow backgrounds to explore colour as a determinant of warning attention. "Cigarettes kill. One in every 3 smokers will die from smoking" was perceived as both direct and informative. This message was formatted with a red and white graphic device.

\section{SURGEON GENERAL'SWARNING: Quitting Smoking} Now Greatly Reduces Serious Risks to Your Health.

Four warning formats were tested. These included a currently mandated warning (top), "Smokers inhale carbon monoxide" with both white and bright yellow backgrounds, and "Cigarettes kill. One in every three smokers will die from smoking" which was printed in red and white.
Testing THE WARnings

The ultimate goal of the experimental phase of the research was to compare the communication effectiveness of the new warnings with a mandated warning. This was done using sequential timed exposures to a cigarette print ad, followed by masked recall, and aided recognition tests. These three techniques are commonly used by market researchers to test the communication effectiveness of print advertisements.

The controlled ad exposure was achieved using a slide projector with a timed shutter. Immediately after each sequential exposure, subjects are asked to write down what was seen. By systematically varying the exposure length, the researcher is able to measure how quickly and accurately a particular stimulus can be perceived and interpreted. ${ }^{13,14}$

Masked recall involves covering parts of an advertisement after an exposure and requesting that the subject recall what was in the masked area. This research technique reveals which information has been seen and stored in the subject's short-term memory. ${ }^{15-19}$

Aided recognition in this study involved requesting subjects to identify information to which they had been previously exposed from a list that included other similar items. Because the subject's memory is "aided", this technique is considered appropriate for low levels of learning or communication.

Students were recruited from high schools in the Augusta, Georgia area. Parental permission was obtained. The recruitment information indicated that subjects would be shown advertisements; however, to prevent cuing, subjects were not told that the study

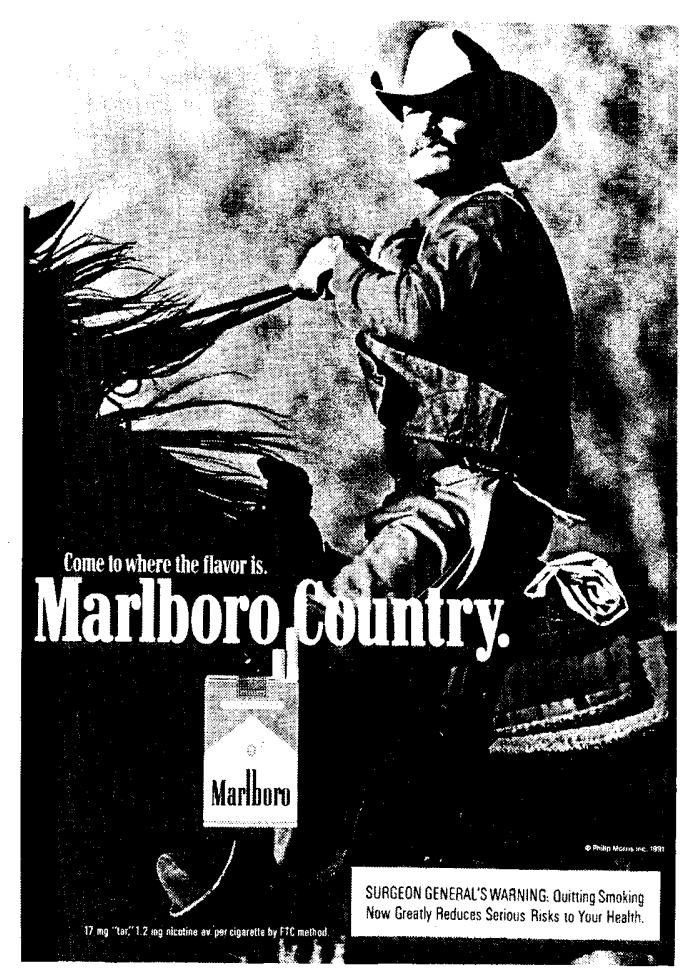

Figure 2 Each warning was placed into this Marlboro advertisement in the right lower corner, for experimental exposures. 


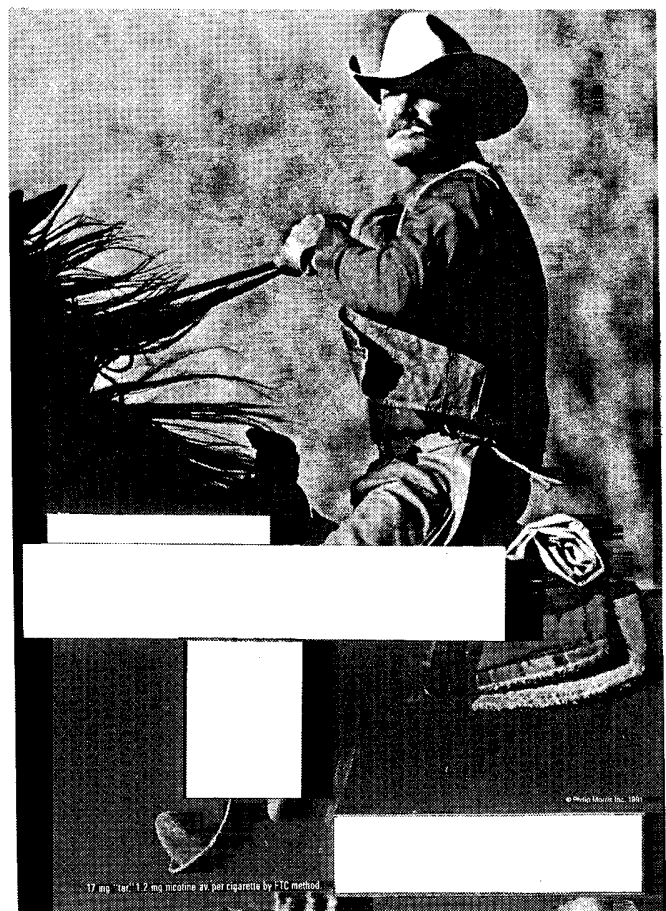

Figure 3 For the recall test, each of the major elements of the Marlboro advertisement was masked. Subjects were asked to record what had been seen in each of these areas of the advertisement.

related to either cigarette advertising or health warnings. The research was approved by the Human Assurance Committee of the Medical College of Georgia.

Students were assigned at random to one of four groups. Each group was exposed to the same Marlboro advertisement containing a different health warning (figure 2). Students were seated in a room where a series of three advertisements was presented by a slide projector equipped with a timed shutter. The first two advertisements were distractor items (ie, advertisements for charcoal lighter fluid and deodorant). One of four versions of the Marlboro advertisement was then presented. Subjects were shown each advertisement nine times with the length of exposure increasing in duration from 0.01 to $2.0 \mathrm{~s}(0.01,0.02,0.05$, $0.10,0.20,0.50,1.0,2.0$, and once more $2.0 \mathrm{~s}$ ). These times were chosen based on both pilot testing and experience from previous eyetracking experiments. ${ }^{3}$ During each interlude, subjects recorded each new element of the advertisement which they had not previously noted.

Following all nine exposures to all three ads,

Table 1 Percentage of subjects reporting three levels of warning communication after a cumulative total of $5.88 \mathrm{~s}$ exposure to a Marlboro advertisement containing either a mandated warning or one of three new warnings (Note: table is cumulative when read from right to left)

\begin{tabular}{lccc}
\hline & $\begin{array}{c}\text { Reported the presence } \\
\text { of a warning }\end{array}$ & $\begin{array}{c}\text { Reported the } \\
\text { warning's concept }\end{array}$ & $\begin{array}{c}\text { Reported the } \\
\text { exact message }\end{array}$ \\
\hline $\begin{array}{l}\text { Mandated warning } \\
\text { "Carbon monoxide" }\end{array}$ & 79 & 15 & 6 \\
(black and white) & 72 & $72^{\star}$ & $46^{\star}$ \\
"Carbon monoxide" & 88 & $81^{\star}$ & $46^{\star}$ \\
"(black and yellow) & 80 & $63^{\star}$ & 2 \\
\hline
\end{tabular}

* $p \leqslant 0.00001$ when comparing this new warning against the mandated warning (chi-square test). subjects were given the masked recall test. A copy of the Marlboro advertisement was masked to cover the major elements (ie, cigarette logo, brand name, cigarette package, and warning; figure 3 ). Subjects were asked to write down as specifically as possible, the content of the masked areas.

Subjects then completed an 11-item paperand-pencil survey that included information about age, grade, socioeconomic status, and cigarette use. One of the survey items was a test of aided recognition. In this item, subjects were asked to circle the text of the warning that was "closest to what you saw in the ad." Three distractor items were included ("Smoking causes lung cancer and heart disease", "Use of cigarettes can lead to emphysema", and "Pregnant women should not smoke"). In each case, the correct response was placed in the second position on the list.

DATA CODING AND ANALYSIS

Information recorded during the controlled ad exposures and recall data were graded based on the subject's ability to identify correctly the major elements in the advertisement. For the warning, this was coded on a hierarchical scale accounting for four levels of comprehension. The first category was the absence of any report of a warning or health advisory. The second category was the indication that a health message was present, but without the message's concept being reported. Next was a report of the warning's health concept. For the mandated warning, this had to at least include the terms "quit" or "quitting" or "reduces" or "risk". It was considered insufficient to merely report "Surgeon General's warning" as evidence that the health concept had been communicated. For the new warnings, reporting of at least "carbon monoxide" or "cigarettes kill" or " 1 in 3 will die" was required. For the fourth communication level, the exact message had to be expressed with only minor grammatical variation.

Aided recognition data were scored as either correct or incorrect, based on respondents circling the warning message to which they had actually been exposed.

In each of the analyses reported, the principal test of difference among responses to the four warnings was the chi-square statistic, because the measures were categorical. Comparisons among the four health advisories for the aided recognition test were made using the studentised range statistic $\mathrm{Q} .{ }^{20}$

\section{Results}

A total of 220 subjects aged between 13 and 19 years were recruited for participation in the experimental phase of this study. Forty-six percent were female, $69.4 \%$ were white, and the remainder were black. Fifty-six percent had never smoked, $33 \%$ had experimented with cigarettes, and $11 \%$ were regular smokers.

We defined a warning as having a minimal level of communication when a subject ident- 
Table 2 Percentage of subjects reporting the presence of a warning during the nine timed exposures

\begin{tabular}{lcccc}
\hline $\begin{array}{l}\text { Number of exposures } \\
\text { (accumulated time in } s)\end{array}$ & $\begin{array}{c}\text { Mandated } \\
\text { warning } \\
(n=53)\end{array}$ & $\begin{array}{c}\text { "Carbon monoxide" } \\
(\text { black and white }) \\
(n=50)\end{array}$ & $\begin{array}{c}\text { "Carbon monoxide" } \\
\text { (black and yellow) } \\
(n=57)\end{array}$ & $\begin{array}{c}\text { "Cigarettes kill" } \\
(\text { red and white }) \\
(n=60)\end{array}$ \\
\hline $\begin{array}{l}1-3 \\
(0.01-0.08 \mathrm{~s})\end{array}$ & 17 & 12 & 11 & 5 \\
$4-6$ & 43 & 30 & 25 & 31 \\
$(0.18-0.88 \mathrm{~s})$ & 19 & 30 & 53 & 45 \\
$7-9$ & 21 & 28 & 12 & 20 \\
$(1.88-5.88 \mathrm{~s})$ & Failed to report warning & 21 & & \\
\hline
\end{tabular}

$\star \mathrm{chi}^{2}$ test of this table: $\mathrm{p} \leqslant 0.017$

Columns do not all equal $100 \%$ due to rounding.

ified the presence of a health advisory. Seventy-nine percent of subjects exposed to the mandated warning reported having seen a health advisory (table 1 ). In contrast, $72 \%$ of subjects exposed to "carbon monoxide" typeset in black on white, $88 \%$ exposed to "carbon monoxide" typeset black on yellow, and $80 \%$ of those exposed to "cigarettes kill" indicated the presence of a health message (table 1). The difference between the mandated warnings and the three newly developed warnings for this variable was not statistically significant.

Although $79 \%$ of subjects exposed to the mandated warning reported the presence of a health message, only $15 \%$ reported the message's concept and only $6 \%$ reported its exact message. This is despite a total of $5.88 \mathrm{~s}$ of cumulative exposure to the ad. In contrast, the newly developed warnings proved to be more effective in communicating both the warning's concept and its exact message (table 1). The differences between the mandated warning and the new "carbon monoxide" warnings were significant for communication of both the concept and the exact message. The "cigarettes kill" warning was statistically su-

Table 3 Percentage of subjects recalling three levels of communication during masked recall test. (Note: table is cumulative as read from right to left)

\begin{tabular}{lccc}
\hline & $\begin{array}{c}\text { Reported the presence } \\
\text { of a warning }\end{array}$ & $\begin{array}{c}\text { Reported the } \\
\text { warning's concept }\end{array}$ & $\begin{array}{c}\text { Reported the } \\
\text { exact message }\end{array}$ \\
\hline $\begin{array}{l}\text { Mandated warning } \\
\text { "Carbon monoxide" }\end{array}$ & 89 & 15 & 0 \\
(black and white) & 88 & $70^{\star}$ & $48^{\star}$ \\
"Carbon monoxide" & 89 & $70^{\star}$ & $44^{\star}$ \\
"Cigark and yellow) & 75 & $60^{\star}$ & 2 \\
\hline
\end{tabular}

$\star \mathrm{chi}^{2}$ test of this level of communication recalled for this new warning against mandated warning: $p \leqslant 0.00001$.

$\therefore$

Table 4 Aided recognition test results. Subjects were asked to circle the statement that was the closest match to the warning that they had seen in the Marlboro advertisement

\begin{tabular}{llc}
\hline Actual warning & \multicolumn{1}{c}{ Test item } & Percent correct \\
\hline $\begin{array}{l}\text { "Surgeon general's warning: } \\
\begin{array}{l}\text { Quitting smoking now greatly } \\
\text { reduces serious risks to your } \\
\text { health" }\end{array}\end{array}$ & $\begin{array}{c}\text { Quitting smoking reduces serious } \\
\text { risk to your health }\end{array}$ & 19 \\
$\begin{array}{l}\text { "Smokers inhale carbon monoxide" } \\
\text { (black and white) }\end{array}$ & Smokers inhale carbon monoxide & 88 \\
$\begin{array}{l}\text { "Smokers inhale carbon monoxide" } \\
\text { (black and yellow) }\end{array}$ & Smokers inhale carbon monoxide & 88 \\
$\begin{array}{l}\text { "Cigarettes kill. One in every 3 } \\
\text { smokers will die from smoking" } \\
\text { (red and white) }\end{array}$ & Cigarettes kill 1 in 3 smokers & 70 \\
\hline
\end{tabular}

* $\mathrm{chi}^{2}$ among four advisories $=75.8, \mathrm{p} \leqslant 0.0001$; studentized comparative range statistic $=$ $0.236, \mathrm{p}=0.05$ (each new warning significantly different from mandated warning). perior to the mandated warning only in communicating the concept.

Not surprisingly in light of prior exposure, the mandated warnings were more rapidly identified as health messages than the new warnings (table 2). The median number of exposures necessary for recognition of the mandated warning as a health message, was five. This compared with six exposures for "carbon monoxide" in black on white, and seven exposures for "carbon monoxide" in black on yellow and for "cigarettes kill."

Successful performance on a masked recall test indicates that the information has been seen, processed, stored in short-term memory, and is available for recall. The mandated warning was recalled to be a health advisory by $89 \%$ of subjects, but only $15 \%$ could recall its health concept (table 3). Each of the newly developed warnings performed better, with a mean of $66 \%$ of subjects able to recall the warning concept.

In the test of aided recognition, subjects were required to choose the warning that they had seen from a list that included three distractor items (table 4). Only $19 \%$ of subjects exposed to the mandated warning correctly identified the item. By contrast, the new warnings were recognised by $70 \%$ to $88 \%$ of subjects. A studentized range statistic was calculated for the four group recognition scores. By this standard, each of the new warnings was significantly superior to the mandated warning at producing recognition ( $p$ $<0.05$ ).

In comparison to the mandated warning, the cigarette advertisement was effective from a communication point of view as $97 \%$ of subjects identified what they saw in the controlled exposure experiment as an advertisement for Marlboro cigarettes. The median cumulative exposure time required to identify the image as a Marlboro cigarette advertisement was only $0.03 \mathrm{~s}$ (ie, exposure number two). Further, $83.1 \%$ of subjects identified the cigarette package and $42.5 \%$ correctly identified the brand slogan ("Come to where the flavor is") during the allotted exposure time. The median times to identify these elements were 0.08 and $3.88 \mathrm{~s}$, respectively.

The major elements of the Marlboro advertisement were readily recalled in the test of masked recall: $81.7 \%$ recalled the major heading ("Marlboro country"), $81.3 \%$ recalled the cigarette pack, and $42.9 \%$ recalled the subheading ("Come to where the flavor is"). 
Table 5 Comparison of communication strategies used in mandated warnings and cigarette advertisements

\begin{tabular}{lll}
\hline Strategy & \multicolumn{1}{c}{ Cigarette advertisements } & \multicolumn{1}{c}{ Mandated warning } \\
\hline Size & $96 \%$ of space & 4\% of space \\
Format & Primarily graphic & Solely textual \\
Targeting & Targeted to specific populations & Not targeted \\
Novelty & Continuously updated & Four rotating messages \\
Style & Image-based & Knowledge-based \\
Development & Based on marketing research & Based on Congressional mandate \\
\hline
\end{tabular}

\section{Discussion}

The federally mandated warning is a small, wordy, colourless, text-based message placed at the periphery of an advertisement. There it must compete for the public's attention with cigarette advertising which has been skillfully crafted, targeted, tested, and regularly updated (table 5).

In this study, and in all previously published research, health warnings mandated by US federal policy performed poorly as communication devices. These warnings are recognised as health advisories but fail to convey any more specific information. One possible explanation for this finding is that the unchanging shape, size, and heading ("Surgeon General's warning") actually discourage further exploration of the message. Current warnings are either "worn out", or may never have been effective.

The process used to develop the new warnings for this study is similar to that used to produce advertisements. The newly developed warnings were shown to be more effective in communicating the risks of smoking when studied with standard tests of communication.

The effectiveness of these new warnings was not simply a result of changes in colour or type. In fact, the use of a bright yellow background provided little advantage over the same warning in black and white. This is in agreement with the work by Popper and Murray who found that increasing the warning size by $40 \%$, changing the type, and changing the background colour, all failed to improve the warning's effectiveness in an experimental setting. ${ }^{21}$ We believe that the critical differences between the mandated and the newly developed warnings have to do with the fact that the latter were novel, were targeted, and were tested as an integral part of the development process. To be effective, warnings must be managed, not merely mandated.

During the past 28 years, the government has attempted to strengthen tobacco warnings by changing their wording, extending them to both cigarette packages and advertisements, adopting rotating messages, and changing the warning's shape. From a communication perspective, these changes represent only "tinkering" with what is a fundamentally limited communication strategy. To be effective, warnings must be managed using the same strategies that are employed to develop the cigarette ads with which they must compete (table 5).

There are several limitations to this research. First, the study population consisted entirely of adolescents. This age group continues to underestimate the health consequences of smoking and is the largest source of future users of cigarettes. ${ }^{22-24}$ Warnings must be effective with adolescents if they are to aid in the primary prevention of cigarette use. It is quite likely that the tested warnings would not be effective for other groups, such as adults, who have been long-term smokers.

Second, we have studied these warnings within the environment of only a single Marlboro advertisement. Without further study, it is impossible to predict how they would communicate in the varied textual elements of other cigarette advertisements.

The experimental test involved a forced exposure to a cigarette advertisement. This is likely to produce the maximal communication effectiveness of the warnings. Real-world exposures to cigarette warnings are less intense and this should result in lower levels of communication than those we observed experimentally. This fact makes the poor performance of the mandated warning all the more troubling.

Finally, the study design cannot eliminate the effect of prior exposure. It is very likely that the subjects had many previous environmental exposures to the mandated warning. It is unclear to what extent this exposure either discouraged further learning or reinforced health messages that had been previously seen. In contrast, the new warnings were completely novel, a characteristic that, in general, encourages communication.

\section{Conclusion}

It is critical that policy makers have a better understanding of what warnings can and cannot accomplish. It is possible that even when optimally designed, in-advertisement health advisories could play only a minor role in a comprehensive programme to educate the public about the risks of smoking.

This limitation has been highlighted by the shift of tobacco marketing practices away from traditional print advertising. Promotional expenditures, not print advertising, now account for the majority of all cigarette marketing expenses. Tobacco companies spent over $\$ 400$ million in 1989 on items such as caps, t-shirts, lighters, racing cars, and signage at sporting events. ${ }^{25}$ Warning labels are either non-existent on these items or are invisible to the television audience watching the sporting event. How effective would the Surgeon General's message be at 200 miles per hour on a Marlboro Grand Prix racing car ?26

The present legislative approach to tobacco warnings protects manufacturers from failureto-warn liability but is ineffective in warning the public. We conclude that this approach to mandated warnings has failed as public health policy and should be replaced by federal policies and programmes that communicate the risks of smoking more effectively.

We would like to thank W Ronald Lane, Otto W Smith, and Robert W Willett, from the Department of Advertising and Public Relations, University of Georgia, who served as the creative team to develop the new warnings. We appreciate the 
prepublication review of this manuscript by Alan Blum, John W Richards, Jr, Richard Daynard, and Edward T Popper. This work was supported by grant PRB-55 from the American Cancer Society, Atlanta, Georgia, USA.

1 Myers ML, Iscoe C, Jennings C, Lenox W, Minsky E, Sachs A. Federal Trade Commission staff report on the cigarette advertising investigation, May 1981 (public cigarette advertising investigation, May 1981 (public
version), Division of Advertising Practices, Federal version), Division

2 Thomas Cipollone v Liggett Group Inc, No 90-1038, US Supreme Court, June 24, 1992.

3 Fischer PM, Richards JW, Berman EF, Krugman DM. Recall and eye tracking study of adolescents viewing tobacco advertisements. $\mathcal{F} A M A 1989 ; 261: 84-9$.

4 Cullingford R, Da Cruz L, Webb S, Shean R, Jamrozik K. Legibility of health warnings on billboards that advertise cigarettes. Med f Aust 1988; 148: 336-8.

5 Davis RM, Kendrick JS. The Surgeon General's warnings in outdoor cigarette advertising: are they readable? fAMA 1989;261: 90-4.

6 Brubaker RG, Mitby SK. Health-risk warning labels on smokeless tobacco products: are they effective? Addict smokeless tobacco produ

7 Beltramini RF. Perceived believability of warning label information present in cigarette advertising. $\mathcal{f}$ Advertising $1988 ; 17: 26-32$.

8 Malouff J. Readability of health warnings on alcohol and tobacco products. Am f Public Health 1992; 82: 464

9 Richards JW, Fischer PM, Conner FG. The warnings on cigarette packages are ineffective. $\mathcal{F} A M A 1989 ; 261: 45$.

10 McGuire WJ. Some internal psychological factors influencing consumer choice. $\mathcal{F}$ Consumer Res 1986; $2: 302-19$.

11 Hill D. Australia's new health warnings on cigarette packaging. Tobacco Control 1992;1:92-4.

12 Basch CE. Focus group interview: an underutilized research technique for improving theory and practice in health education. Health $E d Q 1987$; 14: 411-48.
13 Dunn SW, Barban AM, Krugman DM, Reis LN. $A d$ vertising: its role in modern marketing, edn 7 , Hinsdale, IL: Dryden Press, 1990, p 489.

14 Zikmund WG. Exploring marketing research, edn 3, Chicago, IL: Dryden Press, 1989, p 282

15 Krugman HE. Memory without recall, exposure without perception. F Advertising Res 1977; 17: 7-12.

16 Krugman HE Processes underlying exposure to advertising. Am Psychol 1968; 23: 245-53.

17 Treistman J, Gregg JP. Visual, verbal and sales responses to print ads. F Advertising Res 1979; 19: 41-7.

18 Kroeber-Riel W. Activation research: psychobiological approaches in consumer research. $\mathcal{F}$ Consumer Res 1979 ; 5: $240-50$

19 Leckenby JD, Plummer JT. Advertising stimulus measurement and assessment research: a review of advertising testing methods. Curr Issues Res Advertising 1983, pp

20 Miller RG. Simultaneous statistical inference. New York: McGraw Hill, 1966, pp 37-9.

21 Popper ET, Murray KB. Communication effectiveness and formal effects on in-ad disclosure of health warnings. $\mathcal{J}$ Public Policy Marketing 1989; 8: 109-23.

22 Centers for Disease Control. Selected tobacco-use behaviors, dietary patterns among high school students haviors, dietary patterns among high school stude

23 US Department of Health and Human Services. Smoking and Health: $A$ National Status Report to Congress. Atlanta, Georgia : Centers for Disease Control, 1987. (US DHHS Publication No (PHS) 87-8396.)

24 Silvis GL, Perry CL. Understanding and deterring tobacco use among adolescents. Pediatr Clin North Am 1987; 34 : 363-79.

25 Special Report: Federal Trade Commission Report for 1989. Pursuant to the Federal Cigarette Labeling and Advertising Act. Tobacco Control 1992; 1: 73-7.

26 Blum A. The Marlboro Grand Prix: circumvention of the television ban on tobacco advertising. $N$ Engl $f$ Med $1991 ; 324: 913-7$.

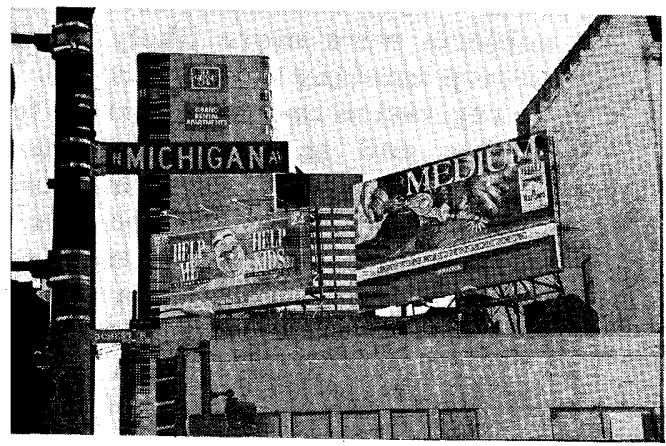

